\title{
A Case Report on Maculopapular Skin Rash Due to Amoxicillin Hypersensitivity Reaction
}

\author{
Satish Kumar B P1, Anwitha Johns ${ }^{2 *}$, Lavanya P R ${ }^{2}$, Pudota Mary Pravallika ${ }^{2}$ \\ ${ }^{1}$ Associate Professor, Department of Pharmacy Practice, Sri Adichunchanagiri College of Pharmacy, Adichunchanagiri University, \\ Mandya, Karnataka, India. \\ 2Pharm D Interns, Department of Pharmacy Practice, Sri Adichunchanagiri College of Pharmacy, Adichunchanagiri University, Mandya, \\ Karnataka, India. \\ *Corresponding author's E-mail: anvithajhons@gmail.com
}

Received: 14-11-2020; Revised: 25-12-2020; Accepted: 04-01-2021; Published on: 15-01-2021.

\section{ABSTRACT}

In the primary care setting Amoxicillin is one of the most widely used antibiotics. Amoxicillin in combination with a beta-lactamase inhibitor is widely preferred i.e combination with clavulanic acid or sulbactam. The major complication to be aware of is hypersensitivity reactions caused by amoxicillin. Amoxicillin can develop type-I, II, III, or IV reactions. A type-IV hypersensitivity reaction is more papular or morbilliform and often not itchy. As a part of our daily routine ward rounds, we came across a case of maculopapular skin rashes on the lower back portion of a 60 years diabetic female patient. These maculopapular rashes were found to be crimson red with severe itching. The reason for this was turned out to be drug-induced maculopapular rashes by amoxicillin/clavulanate. Since a majority of cases are reported on the adverse drug reactions on amoxicillin, it is important to have close monitoring of the patients who are prescribed with the drug amoxicillin or its combinations.

Keywords: Maculopapular skin rash, Amoxicillin, Penicillin, Adverse drug reactions, beta-lactam antimicrobials, Hypersensitivity reactions.

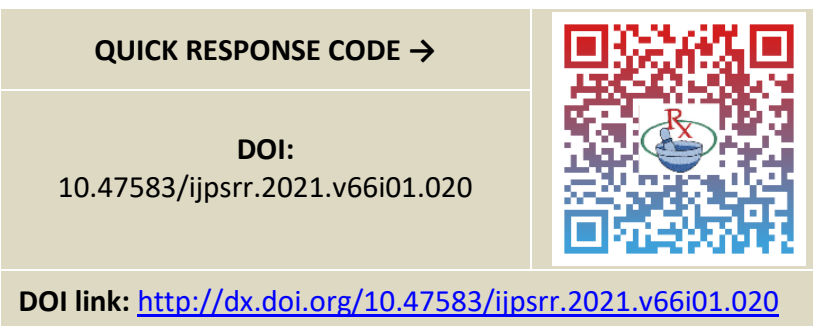

\section{INTRODUCTION}

$\mathrm{n}$ the primary care setting Amoxicillin is one of the most widely used antibiotics. It is produced by adding an extra amino group to penicillin, to overcome antimicrobial resistance. Hence amoxicillin as an aminopenicillin useful against a wide variety of gram-positive bacteria and also few gram-negative when compared to penicillin. ${ }^{1}$

Amoxicillin is under beta-lactam antimicrobials. Betalactams inhibit the cross-linking process in cell wall synthesis(transpeptidation) by binding to penicillinbinding proteins which are responsible for the activation of autolytic enzymes in the bacterial cell wall. Thus leads to the death of the cell wall thereby the destruction of the bacterial cell. ${ }^{2}$

Amoxicillin in combination with a beta-lactamase inhibitor is widely preferred i.e combination with clavulanic acid or sulbactam. These beta-lactamase inhibitors bind irreversibly to the catalytic site of a bacteria's betalactamase enzyme, which roots resistance to the original beta-lactam ring of amoxicillin. These compounds do not have bactericidal activity like amoxicillin, however, when combined with amoxicillin, they may extend amoxicillin's spectrum of activity. The major complication to be aware of is hypersensitivity reactions caused by amoxicillin. Amoxicillin can develop type-I, II, III, or IV reactions. It is essential to single out between a type-I and type-IV hypersensitivity reaction because one may be more dangerous than the other. A type-I reaction is an IgEmediated hypersensitivity to a sensitized patient that generates widespread histamine release causing urticarial like a pruritic rash or more severe systemic symptoms. A type-IV hypersensitivity reaction is more popular or morbilliform and often not itchy. Experts advise that almost all patients who receive amoxicillin for infectious mononucleosis develop a maculopapular rash caused by a type IV-mediated hypersensitivity reaction. ${ }^{1}$

\section{CASE REPORT}

A 60 years old female patient was admitted to the medicine ward, unit C (IP No 20-316) of Adichunchanagiri Hospital and Research Centre with complaints of burning sensation and multiple wound over both the foot from fifteen days. Since the patient was a known case of type 2 diabetes mellitus, final diagnosis based on complaints was concluded as diabetic foot. The patient was administered with Amoxicillin/clavulanate injection which is $1.2 \mathrm{gm}$ as the primary treatment for the diabetic foot. After the second dose amoxicillin clavulanate with an interval of $8 \mathrm{hr}$ to $10 \mathrm{hr}$, the patient started developing itching and had maculopapular reaction over the lower back within half an hour as showed in Figure 1. By observing the patient's 
situation, it was considered to discontinue the treatment with amoxicillin and clavulanate and advised to switch on to injection ceftriaxone and calamine lotion as the local applicant to relieve from rashes and control further allergy. On examination, the patient was conscious, oriented and stable with the pulse rate of $98 / \mathrm{min}$. As a part of counselling, when the patient was assessed for the medical history, the patient revealed that the same such experience had occurred when she was administering the antibiotics before. But patient and the bystanders could not confirm the in taken antibiotic. By considering the above facts we have assessed the present data on causality assessment scale for which the outcome obtained from it was definite.

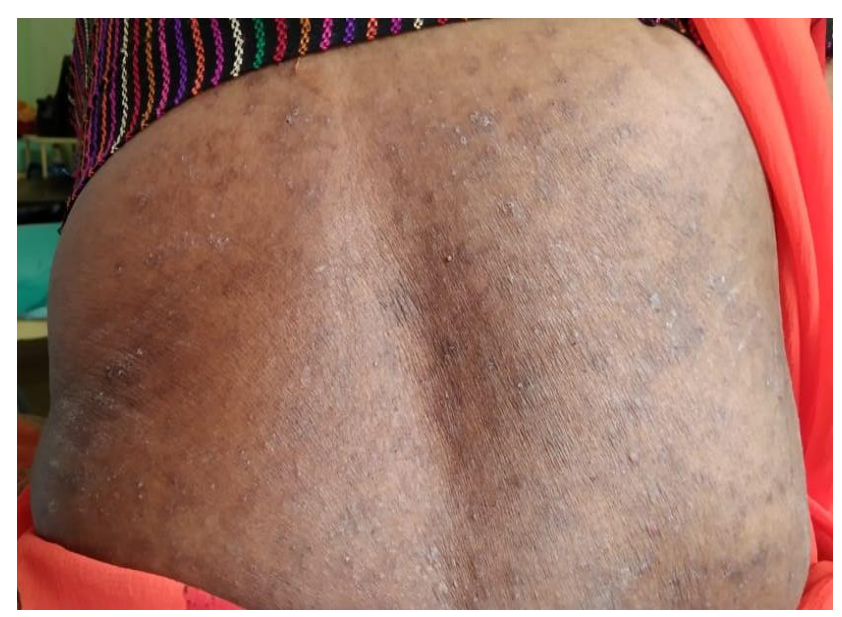

Figure 1: Maculopapular rashes on the lower back

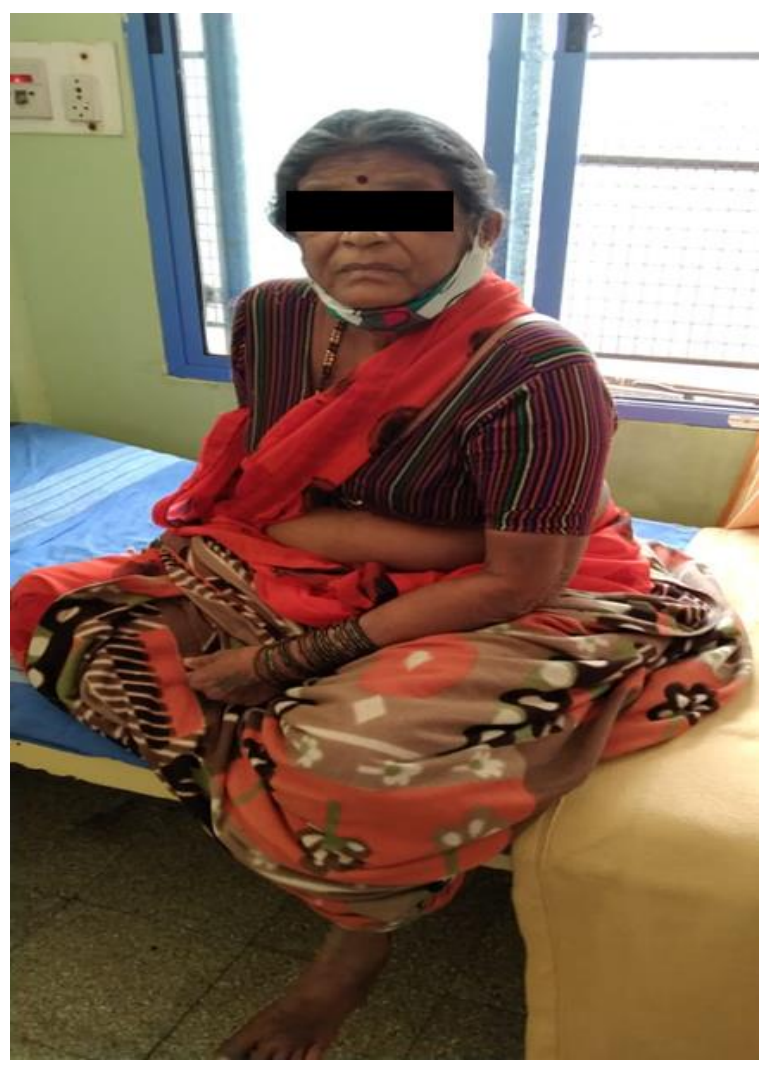

\section{DISCUSSION}

As a part of our daily routine ward rounds, we came across a case of maculopapular skin rashes on the lower back portion of a 60 years diabetic female patient. These maculopapular rashes were found to be crimson red with severe itching. The reason for this was turned out to be drug-induced maculopapular rashes by amoxicillin/clavulanate. The previous studies convey that around $10 \%$ of the population administered with betalactams were prone to such allergic reaction which was reported globally. ${ }^{3}$ Prescribed medicines commonly cause adverse drug reactions found in diverse forms. Maculopapular skin rash is one such adverse drug reactions associated with amoxicillin developed due to an immune-mediated hypersensitivity reaction. Maculopapular skin rashes consist of distinct flat areas (macules) and raised lesions (papules). They are commonly erythematous, may or may not be associated with itching. The reactions may be localized or spread all over the body causing generalized eruptions. These reactions are frequent in paediatrics but reported in adults too. Walli Mohammed, Sushanta Kr. Das, Shardha Srikanth et.al, reported the similar case in a 48-year-old male patient of India visited out-patient department (OPD) of general surgery on October 15, 2014, at around 09:00 AM with a complaint of pain and swelling in the penis and was diagnosed as paraphimosis. ${ }^{4}$ Ashok Kumar Malpani, Riyaz Miya et.al, reported Amoxicillin Induced Immediate Allergic Reaction in a one year seven days old male baby was admitted to the paediatric ward of Gulbarga Institute of Medical Science Hospital with complaints of hyperthermia from four days and multiple abscesses on the head since one month. ${ }^{5}$ Management of amoxicillin induced skin reactions involves early recognition and withdrawal of the particular drug, rapid initiation of supportive care by fluid and electrolyte replacement, symptomatic treatment with antihistaminic drugs and topical applications like calamine and liquid paraffin, helps relieve itching and skin rash. ${ }^{4}$ In our case the 3 In our case, Amoxicillin/clavulanate injection was withdrawn and antihistaminic (pheniramine maleate) were used along with topical skin protecting lotion like calamine, aloe vera and liquid paraffin, which resulted in the complete reduction of rashes.

\section{CONCLUSION}

Since a majority of cases are reported on the adverse drug reactions on amoxicillin, it is important to have close monitoring of the patients who are prescribed with the drug amoxicillin or its combinations. Patients should be made to understand that they are allergic to amoxicillin and should be provided with ADR alert card which should be asked to carry whenever they consult a doctor. Physicians must be aware to ask if any history of allergy to amoxicillin before filling the prescription. This study also reveals the necessity of clinical pharmacists in the ward rounds. 


\section{REFERENCES}

1. Kwon YH. Amoxicillin. In: Helicobacter pylori [Internet]. Springer Singapore; 2016 [cited 2021 Jan 9]. p. 387-96. Available from: https://www.ncbi.nlm.nih.gov/books/NBK482250/

2. Beta-lactamase inhibitors [Internet]. 2015 Jan [cited 2021 Jan 9]. Available from: www.lahey.org/Studies/.

3. Rebelo Gomes E, Fonseca J, Araujo L, Demoly P. Drug allergy claims in children: From self-reporting to confirmed diagnosis. Clin Exp Allergy. 2008 Jan;38(1):191-8.
4. Mohammed W, Das SK, Srikanth S, Uma V, Rao M. IJBCP International Journal of Basic \& Clinical Pharmacology Maculopapular skin rash due to amoxicillin tri-hydrate hypersensitivity reaction: a case report. Int J Basic Clin Pharmacol [Internet]. 2017 Jan 20 [cited 2021 Jan 9];1(1):175-8. Available from: www.ijbcp.com

5. Kumar Malpani A, Miya R, Teja P, Shankar Reddy B. Amoxicillin Induced Immediate Allergic Reaction-A Case Report. Indian J Pharm Pract [Internet]. [cited 2021 Jan 9];13. Available from: www.ijopp.org

Source of Support: None declared.

Conflict of Interest: None declared.

For any question relates to this article, please reach us at: editor@globalresearchonline.net

New manuscripts for publication can be submitted at: submit@globalresearchonline.net and submit_ijpsrr@rediffmail.com 